\title{
Age-estimation of the Christmas Tree Worm Spirobranchus giganteus (Polychaeta, Serpulidae) Living Buried in the Coral Skeleton from the Coral-growth Band of the Host Coral
}

\author{
Eijiroh Nishi*1 and Moritaka Nishihira*2 \\ ${ }^{*}$ Natural History Museum and Institute, Chiba, Aoba \\ 955-2, Chuo, Chiba 260, Japan \\ ${ }^{*}$ Biological Institute, Graduate School of Science, Tohoku University, \\ Aoba, Sendai 980-77, Japan
}

(Received September 25, 1995)

\begin{abstract}
The tubicolous polychaete, Spirobranchus giganteus lives buried in coral skeletons. Its age and longevity were estimated indirectly from the annual coral-growth rings of the host coral counted on soft Xrays radiographs. Since the polychaete tube grows 0.2 to $1 \mathrm{~mm}$ per year in orifice diameter, some had lived more than 10 years, and a few had lived more than 40 years. The application of soft X-rays for age determination of coral associated polychaete is useful for determining the correct age.
\end{abstract}

Key words: tubicolous polychaete, Spirobranchus giganteus, coral-growth ring, age and longevity

Polychaetous annelids are used as fish bait and are an important component of fouling organisms. Serpulid polychaete is representive of the latter, and are well studied in fisheries (e.g., Okamoto et al. $\left.{ }^{1}\right)$ ). Spirobranchus giganteus appears in intertidal to subtidal zones as a typical species of coral reef polychaetes.

There is little accurate data on the longevity of polychaete worms, ${ }^{2,3)}$ mainly because of the difficulty in monitoring them in the field, especially for long-living large species. Among such species, Spirobranchus giganteus is the most remarkable, mostly living buried in coral skeletons. ${ }^{4)}$

We assumed it is possible to estimate the age of S. giganteus by counting the annual growth bands in the coral skeleton overlaying polychaete tubes. Soft X-radiographs of slabs cut along the growth axis of many massive corals displayed alternating dark and light bands which outline the former positions of the outer surface of the colony.") These dark and light bands represent variations in the density at which the skeleton was deposited. A pair of bands-high density and low density (i.e., light plus dark bands)-represents one year's growth. ${ }^{5-8)}$ The annual nature of the banding pattern has since been confirmed for a variety of massive corals from different parts of the world using various dating techniques. ${ }^{5-8)}$

Spirobranchus giganteus and S. polyceros have been found in many coral species, and the age of the latter species was roughly estimated from the coral-growth data." Spirobranchus giganteus grows on coral surfaces covered by living tissues, and its tube is always covered by coral skeleton. Thus, the orifice of the serpulid tube is always present on the surface of living coral.

Spirobranchus giganteus occurs on Porites spp. in Okinawa. ${ }^{(0)}$ We collected some massive Porites with polychaetes and estimated their annual growth.

\section{Materials and Methods}

Ten coral colonies of Porites lutea with 11 polychaete worms were collected at Zampa Cape, central Okinawa Island, from June through September 1993, and in November and December 1994. Coral skeletons were dried after rinsing with synthetic detergent. Coral skeletons were sliced into 2 to $5 \mathrm{~mm}$ thick slices at the area including the polychaete tube, then radiographed under soft X-rays (Softex, MB3, Hitachi). The exposure was $40 \mathrm{kVp}, 3 \mathrm{~mA}$, for 4 to 5 minutes. The source to subject distance was 50 $\mathrm{cm}$. The areas of interest of these soft X-radiographs are shown in Fig. 1.

\section{Results}

Coral-growth bands were usually formed at 0.2 to 1.0 $\mathrm{cm}$ intervals, with a white band usually 0.2 to $1.0 \mathrm{~cm}$ in thickness and a black band 0.1 to $1.0 \mathrm{~cm}$ in thickness (Figs. 1 and 2), and coral had probably grown 0.5 to 1.0 $\mathrm{cm}$ per year. The growth increment of the polychaete tube was usually 0.2 to $1.0 \mathrm{~mm}$ per year in orifice diameter (ranged from 0 to 1.2 , average $0.6 \mathrm{~mm}, N=31$ ), and the growth rate varied greatly among individuals and between years (Fig. 3).

Usually we prepared one or two slices per worm, with a maximum of 10 per worm, and the slice included the whole or only a part of the tube (Fig. 1). If the slice included the whole tube cut longitudinally as shown in Fig. 1 (A and B), the exact growth dates could be determined (Fig. $3)$. If the slice included two openings of the same tube as shown in Fig. 1D, the growth rate between the two openings could be determined accurately (Fig. 3). Some slices, however, contained only one opening clearly cut horizontally, so we could only compare the size of recent tube 

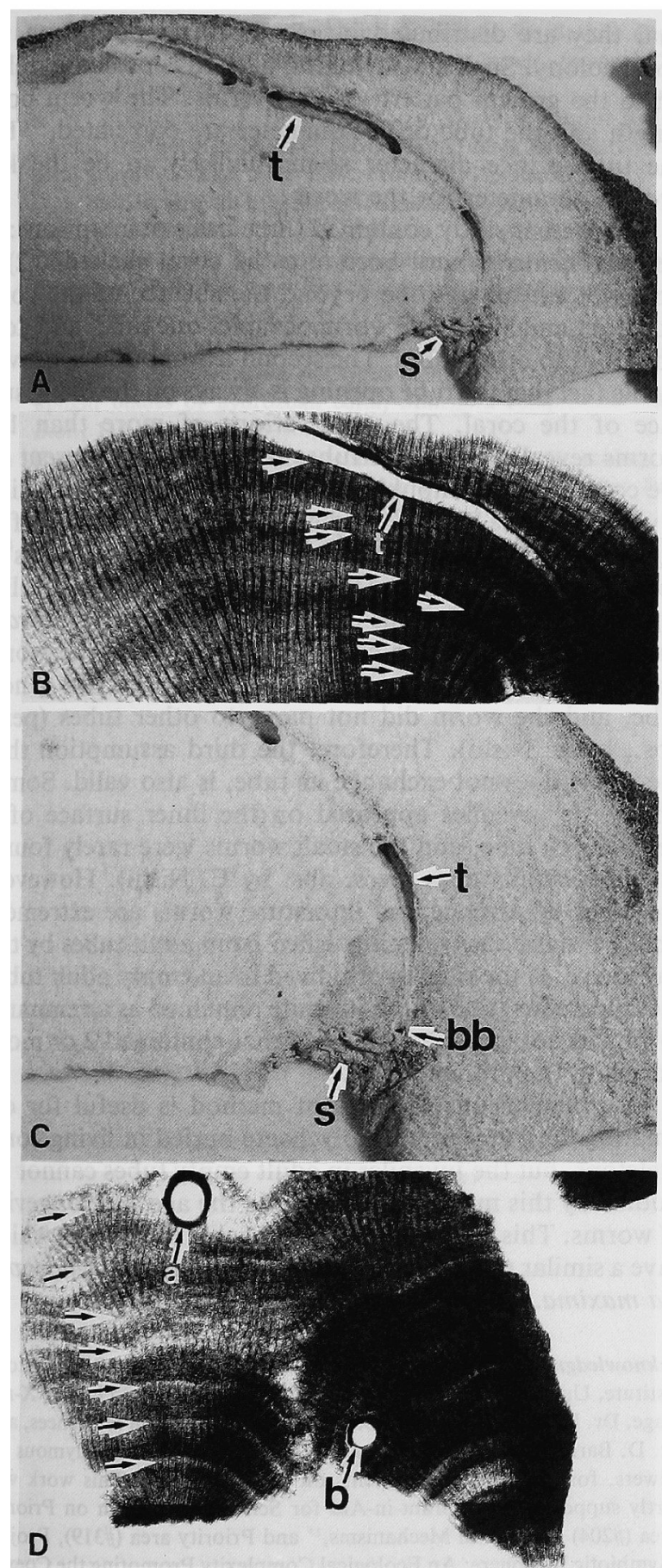

Fig. 1. Photos of slices and soft X-ray micrographs of coral skeletons of Porites lutea and tubes of Spirobranchus giganteus; arrows show one year representing annual growth.

A, photo of the slice of worm D showing a longitudinal section; B, soft X-ray micrograph of the slice of worm D; C, close-up view of the slice of worm $D$, showing the settlement site of the worm on the coral skeleton and the beginning part of the tube buried in the coral skeleton; D, soft X-ray micrograph of worm $\mathrm{C}$, showing two openings of the same tube. $a$ and $b$, opening of worm $C$; bb, beginning part of the tube buried in the coral skeleton; s, settlement position of the worm; $t$, tube of Spirobranchus.

openings on the coral surface with the opening that appeared in the slice. (Figure 3 shows that the diameter of the

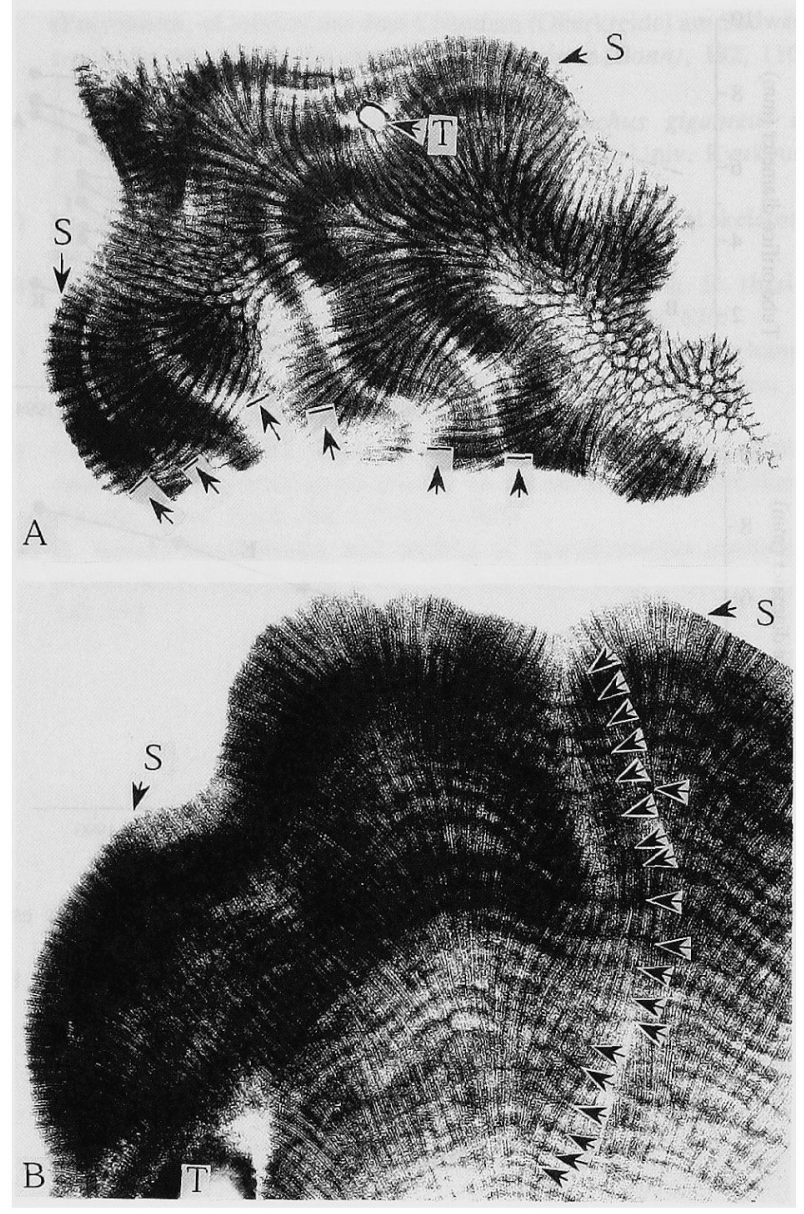

Fig. 2. Radiographs of coral skeletons of Porites lutea and tubes of Spirobranchus giganteus.

Arrows show one year representing annual growth, bars with an arrow show a pair of white and black bands, $T$ and $S$ show the tube of serpulid and surface of the coral colony. Upper radiograph shows colony $\mathrm{F}$, lower shows colony $\mathrm{E}$.

opening and the number of growth bands between the recent tube opening and the opening in the slice.)

Some examples of the growth of different individuals over time are depicted in Fig. 3. Worm A grew slowly, with the orifice diameter increasing about $2.5 \mathrm{~mm}$ from 1989 to 1994 (Fig. 3). On the contrary, worms C and D grew rapidly, their orifice diameters increasing $4 \mathrm{~mm}$ over 5 years (Fig. 3). Worm B did not grow during 1985 and 1986 (Fig. 3). Worm E grew very slowly, and its age was estimated at more than 40 years (Fig. 3, bottom graph, see also Fig. 2, bottom radiograph).

On the slices of coral skeleton, it was in some cases possible to trace the tube back to the settlement position of the polychaete. On such slices, the recruitment site could be determined always on the dead parts of the coral skeleton. Three worms formed a calcareous inner wall (tabulae) at the middle portion of the tube (as in other serpulids, see Lommerzheim ${ }^{11)}$ ), below which the posterior portion could not be traced back because of damage to the tubes. 



Fig. 3. Growths in orifice diameter of Spirobranchus giganteus estimated from annual growth bands of coral skeletons.

Bottom graph shows the growth of worm $\mathrm{E}$ which showed the slowest and longest growth.

\section{Discussion}

This study showed that Spirobranchus lived for more than 10 years, and sometimes more than 40 years. The annual tube growth in orifice diameter was estimated at 0.2 to $1.0 \mathrm{~mm}$, so that a worm with an orifice diameter of $>10 \mathrm{~mm}$ is probably at least 7 to 10 years old. Tube orifice diameters recorded in the field were mostly between 3 to 12 $\mathrm{mm}$ in Okinawa, ${ }^{12)}$ with the maximum size being $>14$ mm. ${ }^{13)}$ Therefore, some Spirobranchus live for 10 or more years, and some live beyond that age.

It is very impressive that a worm, with a body length not surpassing $10 \mathrm{~cm}$, can live for more than 40 years. But the congener associated with living corals has been reproted to live a very long life; Spirobrachnus polycerus, smaller (body length up to $5 \mathrm{~cm}$ ) than $S$. giganteus, lives more than 10 years, ${ }^{9}$ and $S$. giganteus was estimated to live more than 20 years in Australia. ${ }^{14)}$ The massive Porites has a longer life span, reaching a diameter of more than $5 \mathrm{~m}$ (pers. obs. by $M$. Nishihira), indicating a life of more than 100 years, because the annual growth rate of massive corals is usually 5 to $\left.15 \mathrm{~mm} .{ }^{15}\right)$ The longer life span of host corals seems to be related to the longer life of Spirobranchus. The worm $\mathrm{E}$, which has the maximum longevity, is probably a rare case, and we can estimate the longevity of this species to be usually 10 to 20 years, and rarely 30 .

The growth rate of the worm represented by tube orifice diameter varied greatly as shown in Fig. 3. It is likely that the increase in tube diameter is affected by the available food, and this parameter seems to depend on the habitat or position of the colony. Dai and Yang ${ }^{16}$ studied Spirobranchus at Taiwanese coral reefs, and concluded that they are distributed in groups or randomly on the coral colony. Such a distribution pattern is probably related to the growth pattern of the worms. The worm body length and the tube orifice diameter are correlated, ${ }^{(0)}$ but the tube orifice diameter seems unlikely to be the key growth parameter for the worm.

The present study contained three basic assumptions: 1) Spirobranchus cannot bore into the coral skeleton, 2) it does not extend its tube beyond the surface of the coral skeleton, and 3) a single worm occupies one tube, and does not move to other tubes. The second assumption is proven by the fact that the tube opening is always on the living surface of the coral. The observations of more than 100 worms revealed that their tubes were certainly present on the coral surface (unpublished data). The first assumption is valid, because $S m i t h^{17)}$ studied the larval settlement of $S$. giganteus and concluded that they settled on dead areas of coral skeletons and extend their tubes directing into the living part of the coral. Thus we can conclude that Spirobranchus does not bore into coral skeletons. When the worm was pulled out from the tube, it could not secrete a new tube, and the worm did not move to other tubes (pers. obs., by E. Nishi). Therefore, the third assumption that the worm does not exchange its tube, is also valid. Sometimes, the juveniles appeared on the inner surface of a dead empty tube, and the small worms were rarely found in empty adult tubes (pers. obs. by E. Nishi). However, the tubes of juvenile and immature worms are extremely small, and are easily distinguished from adult tubes by the naked eye. If the small worm lived in an empty adult tube, the calcareous tube of the juvenile remained as a remnant, so we did not include such tubes that contained 2 or more worms in the present study.

As a conclusion, the present method is useful for estimating the longevity of polychaete buried in living coral skeletons, but the juveniles in adult empty tubes cannot be studied by this method to determine the age and longevity of worms. This method is also applicable to animals which have a similar mode of coral utilization, such as Dendropoma maxima.

Acknowledgments We wish to thank Dr. H. Yamashiro, Radioisotope Institute, University of the Ryukyus, for his technical help in soft X-ray usage, Dr. Harry A. ten Hove, for sending us some useful references, and Dr. D. Barnes, Australian Oceanographic Institute, and anonymous reviewers, for their useful comments on the manuscript. This work was partly supported by a Grant-in-Aid for Scientific Research on Priority Area (\#204) "Dispersal Mechanisms," and Priority area (\#319), Project "Symbiotic Biosphere: An Ecological Complexity Promoting the Coexis. tence of Many Species" from the Ministry of Education, Science and Cul. ture, Japan.

\section{References}

1) K. Okamoto, A. Watanabe, H. Watanabe, and K. Sakata: Induction of larval metamorphosis in serpulid polychaetes by L-DOPA and catecholamines. Fish. Sci., 61, 69-74 (1995).

2) S. V. Smith and E. C. Haderlie: Growth and longevity of some calcareous fouling organisms, Monterey Bay, California. Pac. Sci, 23, 447-451 (1969).

3) B. H. Grave: Rate of growth, age at sexual maturity, and duration of life of certain sessile organisms, at Woods Hole, Massachusetts. Biol. Bull., 65, 375-386 (1933).

4) H. A. ten Hove: Serpulinae (Polychaeta) from the Carribean: I, the genus Spirobranchus. Stud. Fauna Curacao, 32, 1-57 (1970). 
5) D. W. Knutson, R. W. Buddemeier, and S. W. Smith: Coral chronometers; seasonal growth band in reef corals. Science, 177, 270-272 (1972).

6) R. W. Buddemeier, J. E. Maragos, and D. W. Knutson: Radiographic studies of reef coral exoskeletons; rates and patterns of coral growth. J. Exp. Mar. Biol. Ecol., 14, 179-200 (1974).

7) D. J. Barnes: Growth in colonial scleractinians. Bull. Mar. Sci., 23, 280-298 (1973).

8) J. M. Lough and D. J. Barnes: Intra-annual timing of density band formation of Porites coral from the central Great Barrier Reef. $J$. Exp. Mar. Biol. Ecol., 135, 35-57 (1990).

9) J. Marsden: Factors influencing the abundance of seven-spined morphotype of Spirobranchus polycerus (Schmarda), (Serpulidae), on uplight blades of hydrozoan coral, Millepora complanata. Mar. Biol., 115, 123-132 (1993).

10) E. Nishi and T. Kikuchi: Preliminary notes on the ecology of Spirobranchus giganteus at Okinawa. Pub. Amakusa Mar. Biol. Lab., 12, 45-54 (1996).

11) A. Lommerzheim: Monographische bearbeitung der Serpulidae
(Polychaeta, sdentaria) aus dem Cenoman (Oberkreide) am Sudwestrand des Munsterlander Bekkens. Decheniana (Bonn), 132, 110195 (1979).

12) E. Kinjo: Population ecology of Spirobranchus giganteus at Kudaka Island, Okinawa. Unpublished B. thesis, Univ. Ryukyus, Okinawa, 1992, p. 120 (in Japanese).

13) E. Nishi: Life of tropical serpulid worm remained in coral skeleton. Iden 49, 72-74 (1995) (in Japanese).

14) R. Smith: Photoreceptors of serpulid polychaetes. P.h. D. thesis, University of North Queensland, Townsville, 1985, p. 670.

15) D. J. Barnes and J. M. Lough: The nature of skeletal density banding in scleractinian corals: fine banding and seasonal patterns. $J$. Exp. Mar. Biol. Ecol., 126, 119-134 (1989).

16) Cheng-Feng Dai and Hsiao-Pei Yang: Distribution of Spirobranchus giganteus corniculatus (Hove) on the coral reefs of Southern Taiwan. Zool. Stud., 34, 117-125 (1995).

17) R. Smith: Development and settling of Spirobranchus giganteus (Polychaeta; Serpulidae). Proc. Ist Polychaete Conf., Sydney, pp. 147-153. 